\title{
Developments in Titanium Research and Applications in Germany
}

\author{
Carsten Siemers $^{1 *}$ and Christian Stöcker ${ }^{2}$ \\ ${ }^{1}$ Technische Universität Braunschweig, Institut für Werkstoffe, Langer Kamp 8, 38106 Braunschweig, Germany \\ ${ }^{2}$ ARCONIC Engines TITAL GmbH, Kapellenstraße 44, 59909 Bestwig, Germany \\ *c.siemers@tu-braunschweig.de
}

Abstract

Since the Ti-2015 World Conference on Titanium held in San Diego, USA, research, development and applications of commercially pure titanium, titanium alloys and titanium aluminides have advanced considerably. In this plenary paper, information is provided on important achievements in the German titanium industry, governmental and non-governmental research organisations and universities from the last four years.

\section{Introduction}

In the last few years the world's titanium industry has grown mainly driven by the aerospace industry. Consequently, since the last Titanium World Conference 2015 in San Diego [1], the German titanium community has continued to increase its output in leading edge titanium research and technology. Multidisciplinary research activities have been carried out by the German titanium industry, research organisations and higher education establishments. Collaborations are, in addition, more and more expanded to European and international institutions.

In Germany, titanium alloy production starts from titanium sponge, which is imported mainly from America and Asia. The GfE Metalle and Materialien $\mathrm{GmbH}$ in Nuremberg (AMG Titanium Alloys \& Coatings) is producing master alloys, advanced titanium alloys and titanium aluminides including scrap recycling. Here, several VAR furnaces with capacitates up to 500 kilograms, VAR skull melters and (cold-crucible) vacuum induction melting furnaces (CCVIM and VIM) up to 2 metric tons are operated. Semi-finished products, forgings, investment castings as well as machined components of several alloys for different industrial applications are manufactured by e.g. AdvantIQx, ARCONIC Engines TITAL GmbH, Liebherr-Aerospace Lindenberg GmbH, Litos/, Otto Fuchs KG, Piller Blowers \& Compressors or VACUCAST GmbH.

In 2018, ARCONIC Engines TITAL GmbH has opened its expanded titanium aerospace parts facility in Bestwig, Germany, to meet growing demand from commercial aircraft customers for lightweight titanium investment castings for the aerospace industry, see figure 1 . The expansion almost doubled the titanium parts production capacity and is enabling an increased production of large titanium structural castings up to 1.5 meters in diameter for leading commercial aircraft platforms. The expanded facility employs the latest advanced manufacturing equipment for more efficient production.

Research in the last four years focused on the development of new alloys and the introduction of sophisticated thermo-mechanical processes mainly for the aerospace industry and medical engineering. This includes a high-strength, aluminium- and vanadium-free alloy for osteosynthesis and implant applications, a thermomechanical process route to achieve high fracture toughness in Ti-17 forgings for applications at elevated temperature, the understanding of the $\beta$-phase texture development in $\mathrm{Ti} 6 \mathrm{Al} 4 \mathrm{~V}$ during compression in the $\alpha+\beta$ regimes and a thermo-hydrogen-treatment to achieve fine-grained metastable $\beta$-alloys with homogeneously distributed $\alpha$-precipitations. In addition, for conventional implant alloys, their native oxide layers have been studied with respect to biologically relevant properties.

Titanium additive manufacturing by powder-bed-fusion processes like selective laser melting (SLM), electron beam melting (EBM) or laser metal deposition (LMD) was investigated in many ways, e.g. to enable the manufacturing of larger radial compressor impellers. Here, processes must be strictly shielded to achieve low oxygen contents in the final parts. In addition, in the binary system titanium-lanthanum $\alpha$ phase transformation path was discovered that opens up an alternative to avoid the typical coarse anisotropic microstructures obtained upon additive manufacturing of conventional titanium alloys. New $\gamma$ TiAl alloy compositions tailored to electron beam melting have been developed. Metal injection moulding (MIM) and 3D-printing have been used to produce small to medium-size parts mainly for medical applications.

To reduce the production costs of conventional titanium alloys and $\gamma$-TiAl, advanced processes like investment casting have been improved, and the capacity of titanium investment casting production has been significantly increased in Germany in the last four years. As intermetallic $\gamma$-TiAl-based alloys are applied in low pressure turbine blades now, $\gamma$-TiAl conversion of reverted parts has been investigated and validated. Parts from induction skull melted revert materials were technically indistinguishable from those being produced from fresh ingots.

In the following sections, major developments and selected (joint) research projects of the last four years are highlighted and briefly described. Further information can be obtained from the individual conference papers and the related conference presentations.

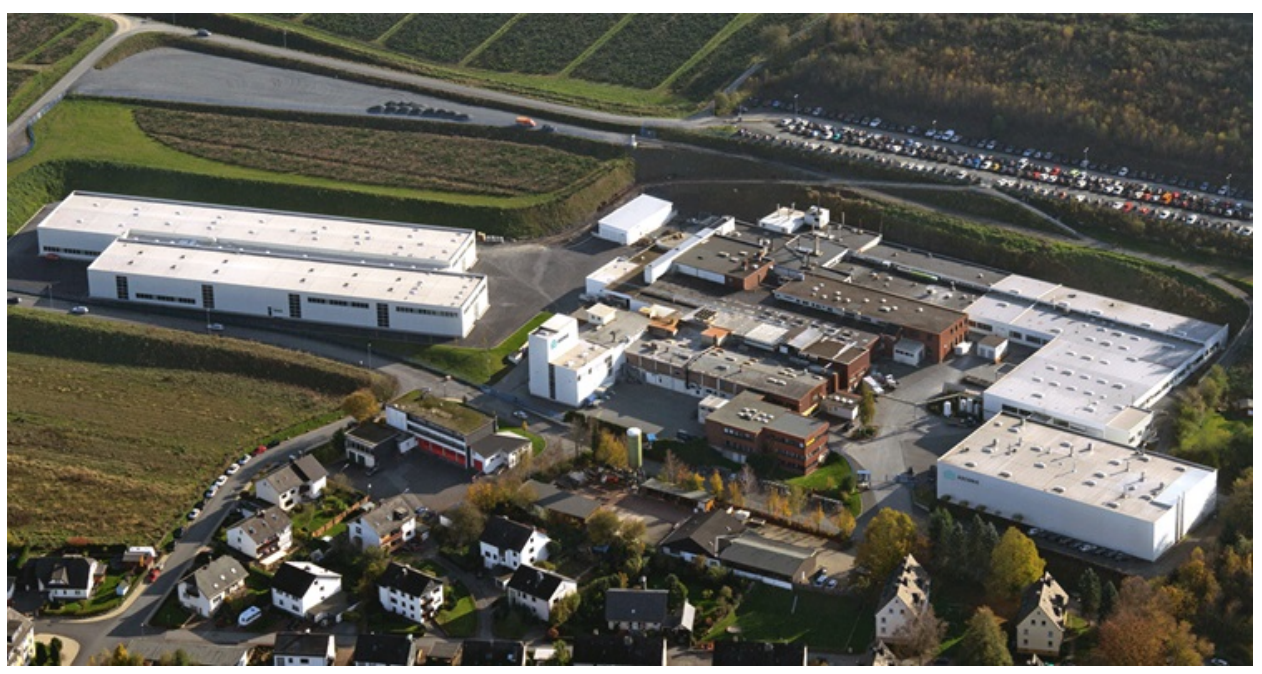

Figure 1: ARCONIC Engines TITAL GmbH operations recently expanded their titanium aerospace parts activities (new hall on the left of the picture).

(C) The Authors, published by EDP Sciences. This is an open access article distributed under the terms of the Creative Commons Attribution License 4.0 (http://creativecommons.org/licenses/by/4.0/). 


\section{Alloy development and production}

TiAl alloy production and products

The production of titanium aluminides at GfE Metalle und Materialien is based on vacuum arc remelting (VAR) of consumable compacted electrodes and subsequent homogenisation in VAR skull melting (VAR SM) furnaces with centrifugal casting in permanent moulds to small sized semi-finished products. The outstanding homogeneity of this material was the most important pre-condition for commercialising TiAl. The vast majority of the TiAl materials is used for the production of low pressure turbines for novel fuel saving civil aircraft engines.

Valuable revert resulting from feeders, casting crowns and pre-shaping of parts is being remelted in induction skull melters (cold crucible VIM) and centrifugal casting according to the virgin production route via VAR SM. Products include as-cast remelt stocks for investment casting, HIPed bars for forging, HIPed and thermally treated pre-shaped parts for direct machining of products, EIGA electrodes for gas atomisation and extruded profiles. Recently an electrode induction gas atomisation (EIGA) furnace has been commissioned in order to produce spherical TiAl and titanium alloy powders for additive manufacturing. GfE operates a well-balanced set of VAR, VAR SM, ISM and EIGA furnaces in order to meet the increasing demand for TiAl based materials, see figure 2.

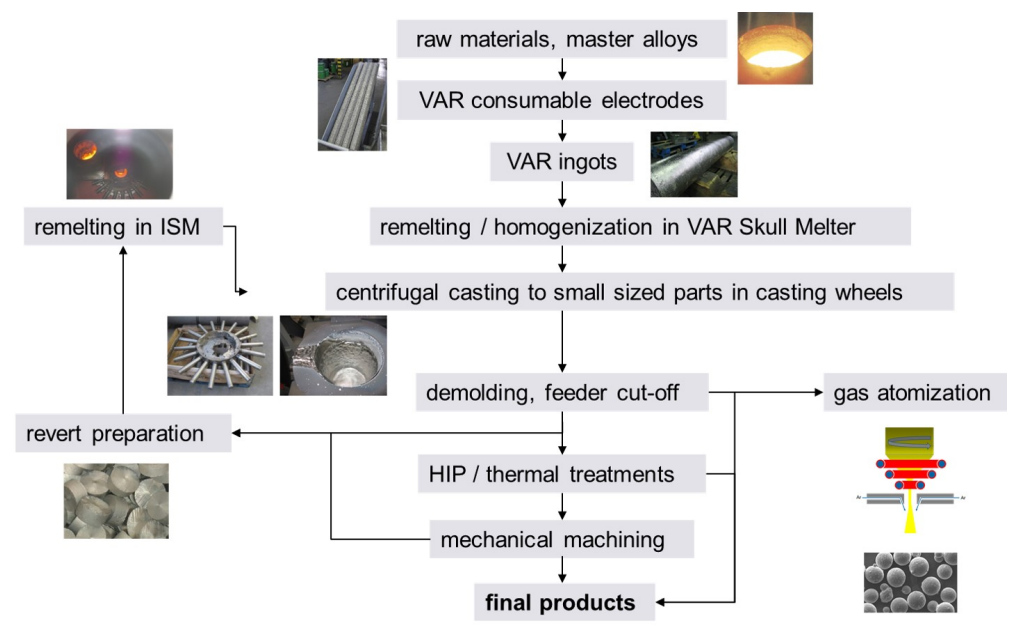

Figure 2: Production capabilities of AMG Titanium Alloys \& Coatings.

Aluminium- and vanadium-free titanium alloys for medical applications

Several alloys on the basis of CP-Titanium Grade 4 (called CP-Ti Grade $4^{+}$, Ti $0.4 \mathrm{O} 0.5 \mathrm{Fe} 0.08 \mathrm{C}$ ) have been developed and studied at the TU Braunschweig, the DECHEMA Forschungsinstitut and Litos, which contain oxygen, carbon, iron, molybdenum, gold, silicon, and niobium as alloying elements instead of aluminium and vanadium [2]. The former four are essential elements in the human body, whereas the latter three are seen as biocompatible [3]. These alloys should possess, on the one hand, similar or even better mechanical properties compared to Ti 6Al 4V (ELI) combined with a better biocompatibility and, on the other hand, a similar corrosion resistance as CP-Titanium Grade 2.

The materials have been produced either in laboratory scale or in larger quantities at VACUCAST, rotary swaged or rolled and subsequently recrystallisation annealed [4]. For instance, figure 3 (a) shows the microstructure of Ti $0.44 \mathrm{O} 0.5 \mathrm{Fe} 0.08 \mathrm{C} 0.4 \mathrm{Si} 0.1 \mathrm{Au}$ (produced in larger quantities) after rolling and recrystallization in longitudinal direction (DIC-contrast). It can be seen that the microstructure consists primarily of fine globular $\alpha_{\mathrm{p}}$-grains, see figure 3 (b), with an average grain size of approx. $11 \mu \mathrm{m}$. However, some retained lamellar structures might still be present. Vickers hardness measurements show a hardness of $334 \mathrm{HV} 10$. Several of the studied alloys exhibit a ductility, yield, and ultimate tensile strength which are above the minimum requirements for Ti 6Al 4V ELI according to ASTM F136. For example, the silicon containing alloy Ti $0.44 \mathrm{O} 0.5 \mathrm{Fe} 0.08 \mathrm{C} 0.4 \mathrm{Si}$ shows a yield strength of approx. $985 \mathrm{MPa}$ with a ductility of $15 \%$. In contrast to silicon, the molybdenum containing alloy Ti $0.44 \mathrm{O} 0.5 \mathrm{Fe} 0.08 \mathrm{C} 2.0 \mathrm{Mo}$ exhibits a yield strength of approx. $1005 \mathrm{MPa}$ in combination with a ductility of at least $17 \%$.

Accordingly, some of the studied alloys might be a possible replacement for Ti 6Al 4V ELI in osteosynthesis and implant applications with similar or even better mechanical properties in combination with a possible higher biocompatibility [5].
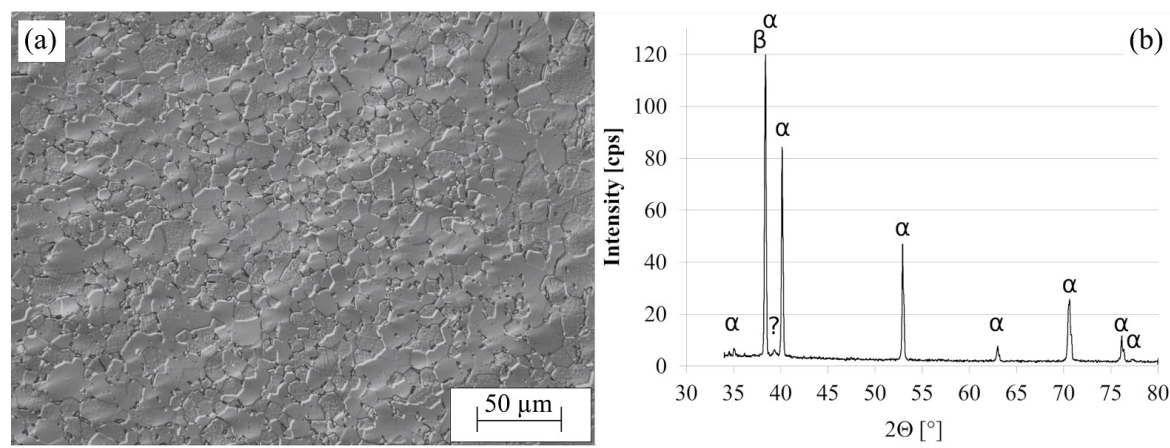

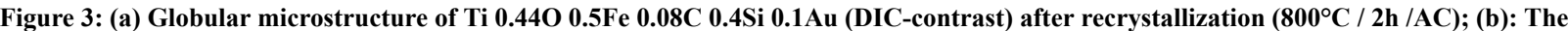
diffraction pattern (smoothed) of the same alloy after recrystallisation $\left(800^{\circ} \mathrm{C} / 1 \mathrm{~h} / \mathrm{AC}\right)$ shows that only $\alpha$ - and $\beta$-phase is present in the alloy.

\section{Thermo-mechanical processing}

A new thermomechanical process route for Ti-17 forgings

The established manufacturing route for Ti-17 aero engine applications is designed to achieve high strength and good low cycle fatigue properties. Through the variation of the thermomechanical process parameters, such as forging and heat treatment temperatures and cooling rates, several processes at Otto Fuchs KG have been developed to achieve high fracture toughness in Ti-17 forgings, which are exceeding the typical values reported in literature. This allows extending the range of achievable properties and possible areas of application. Ti-17 could also be interesting for structural parts, when damage tolerance 
properties are the main driving factors for the design concept. A promising process route leads to isotropic properties, with a good combination of strength, toughness and a uniform micro- and macrostructure, see figure 4.
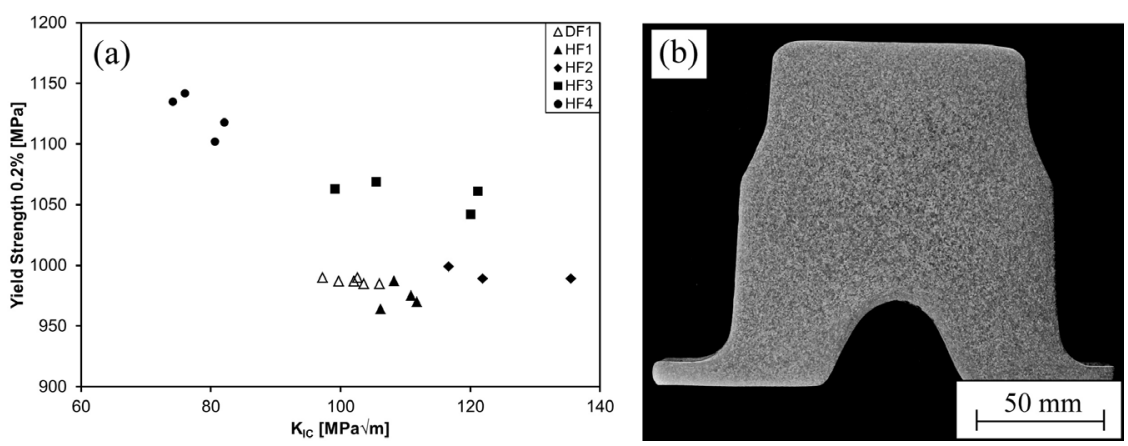

Figure 4:(a) Selection of the achieved properties of the studied Ti-17 process routes; (b) macro structure of a forged Ti-17 part manufactured with the newly developed process route.

Generation of microstructural gradients via thermo-hydrogen treatment of metastable $\beta$-titanium alloys

Structural components have to meet increasing durability and reliability requirements and fulfil the demand of saving resources by lightweight. Hence, new processing techniques must be developed. One approach carried out at the Universität Siegen is to temporarily load titanium alloys with hydrogen which generates lattice distortion and hydrides. The volume difference of the hydride precipitation results in localised plastic deformation triggering recrystallisation and enabling a finer microstructure as attainable by a conventional heat treatment. The aim of the study is the design of a thermo-hydrogen treatment (THT) that establishes a microstructure, which changes purposefully in distribution and morphology of strengthening precipitates as well as in grain size as a function of the distance to surface (microstructural gradient) and therefore increases fatigue life [6,7]. In previous works at Ti $3 \mathrm{Al} 8 \mathrm{~V} 6 \mathrm{Cr} 4 \mathrm{Mo} 4 \mathrm{Zr}$ and $\mathrm{Ti} 10 \mathrm{~V} 2 \mathrm{Fe} 3 \mathrm{Al}$, the necessary data of the reactions were studied [8]. The resulting process employed multiple isothermal heat treatment steps which are performed in hydrogen (hydrogenation), in air (constant hydrogen content) and in vacuum (dehydrogenation). The establishment of a microstructural gradient is either based on a hydrogen concentration gradient or on a gradient in the hydride volume fraction, which are elaborated in this study by variation of the hydrogenation time and temperature, carried out subsequent to a solution treatment. The experiments are performed at a horizontal vacuum furnace with attached $\mathrm{He} / \mathrm{H}_{2}$ gas supply and the parameters vary from $600{ }^{\circ} \mathrm{C}(1,2,4$ and $6 \mathrm{~h})$ to $675^{\circ} \mathrm{C}(2$ and $4 \mathrm{~h})$ for Beta $\mathrm{CTM}$ and from $550^{\circ} \mathrm{C}$ for $1,2,4,6$ and $8 \mathrm{~h}$ to $600^{\circ} \mathrm{C}$ for $1,2,3,4,5$ and $6 \mathrm{~h}$. This generates various hydrogen concentrations, since the hydrogen uptake is diffusion-controlled. Analysis of the resulting microstructures is done by FE SEM to display the grain size and volume fraction gradients qualitatively and is combined with EDS point analysis, to prove redistribution of alloying elements. The hydrogen concentration at accessible areas is determined with carrier hot gas extraction.
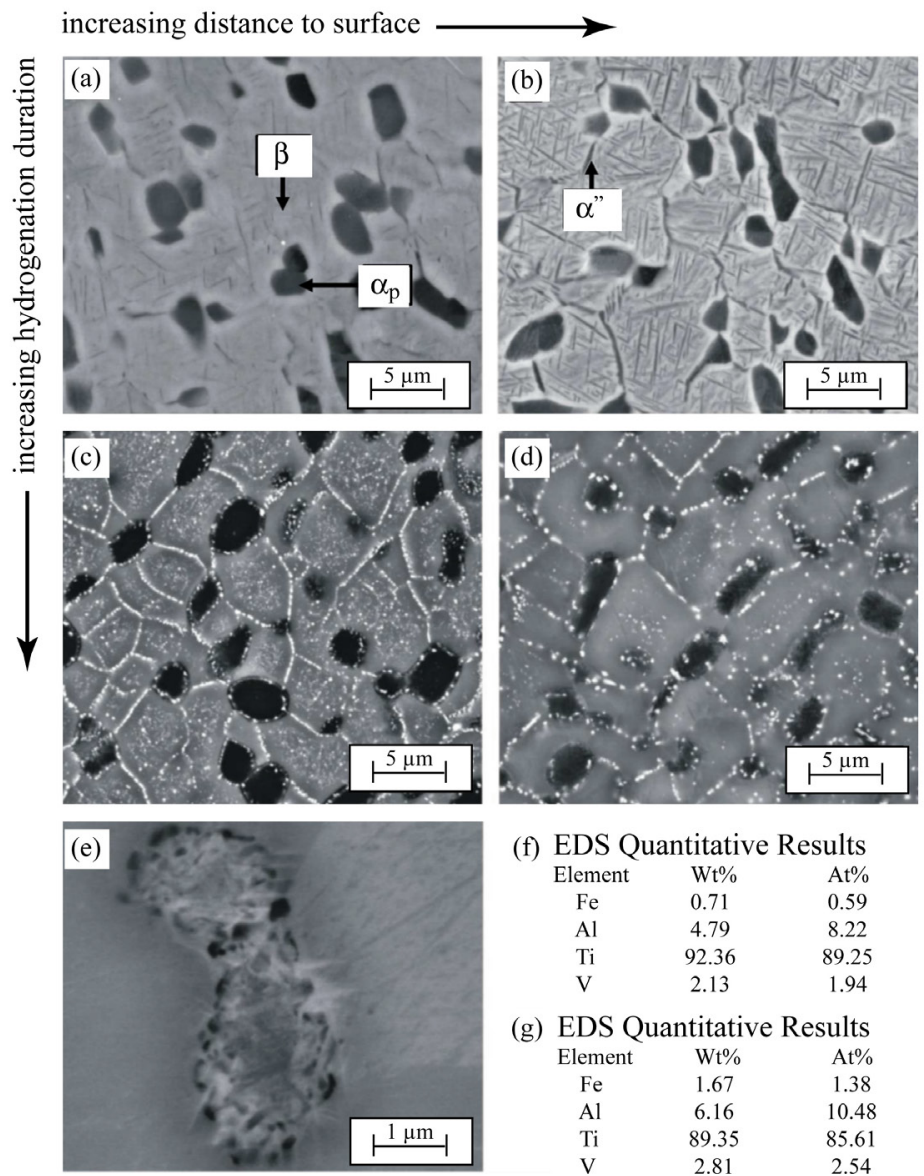

(f) EDS Quantitative Results

$\begin{array}{ccc}\text { Element } & \mathrm{Wt} \% & \mathrm{At} \% \\ \mathrm{Fe} & 0.71 & 0.59 \\ \mathrm{Al} & 4.79 & 8.22 \\ \mathrm{Ti} & 92.36 & 89.25 \\ \mathrm{~V} & 2.13 & 1.94\end{array}$

(g) EDS Quantitative Results

$\begin{array}{ccc}\text { Element } & \mathrm{Wt} \% & \mathrm{At} \% \\ \mathrm{Fe} & 1.67 & 1.38 \\ \mathrm{Al} & 6.16 & 10.48 \\ \mathrm{Ti} & 89.35 & 85.61 \\ \mathrm{~V} & 2.81 & 2.54\end{array}$

Figure 5: FE-SEM micrograph of Ti 10-2-3 after hydrogenation at $600^{\circ} \mathrm{C}$, for $1 \mathrm{~h}$ : (a) surface area (c $\mathrm{c}_{\mathrm{H}}=\mathbf{2 0}$ at.-\%) and (b) center, for 6 h: (c) surface area $\left(c_{H}=40\right.$ at.- $\left.\%\right)$ and (d) surface of the sample and for 3 h ((32 at.- $\left.\left.\%\right)\right)$ : (e) destabilised $\alpha_{p}$-precipitation close to the surface with its EDS point analysis of (f) the residual $\alpha_{\mathrm{p}}$-phase and (g) the destabilised $\alpha_{\mathrm{p}}$-phase from (e). 
Properties' optimisation of aerospace parts by sophisticated thermo-mechanical treatments

Different titanium alloys are used at Liebherr-Aerospace Lindenberg GmbH for aeronautical applications in landing gear and flight control systems. For these applications, the mechanical properties of conventionally as well as additively manufactured alloys $(\alpha+\beta$, metastable $\beta$ ) were optimised by adapted thermomechanical treatments e.g. to improve the hardening process of large cross-sections made of metastable b-alloys. This process modification allowed controlling the volume fraction of the primary a-phase enhancing the fatigue properties and the ductility. In addition, for a fatigue critical forging part made from an $(\alpha+\beta)$ alloy, a slight modification of the chemical composition combined with an additional heat treatment step during the forging process was performed. This improved the fatigue behavior of the finished part.

$\mathrm{Ti} 6 \mathrm{Al} 4 \mathrm{~V}$ parts produced by additive manufacturing, printed with optimised parameters followed by a dedicated heat treatment resulted in improved fatigue properties in all printing directions by reducing the anisotropy of the printed parts. Figure 6 shows the microstructure development of Ti $6 \mathrm{Al} 4 \mathrm{~V}$ part during the additive manufacturing process starting from the powder ((a) and (b)), followed by a stress relieving (c) and a heat treatment below $\beta$-transus combined with hipping (d). This microstructure deviates from the one of standard annealed bars and forgings.
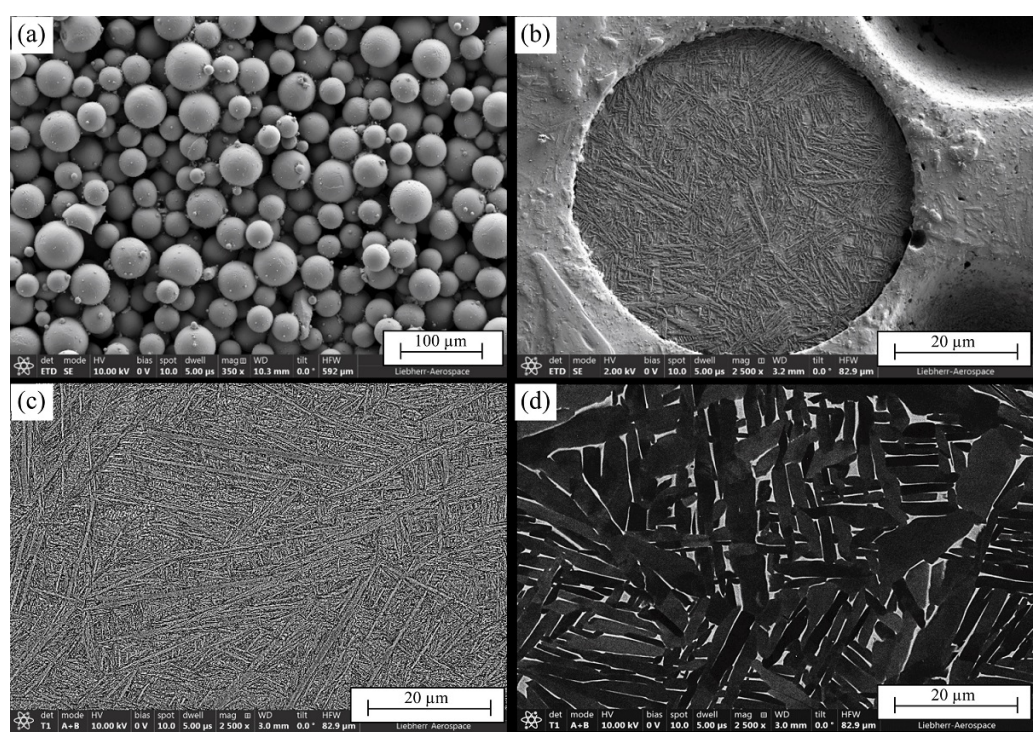

Figure 6: SEM micrographs of (a) Ti 6Al 4V powder with a mean particle size of about 50 $\mu \mathrm{m}$, (b) microstructure of Ti 6Al $4 \mathrm{~V}$-powder particle showing $\alpha$ ' martensite needles, (c) $\alpha^{\prime}$ martensitic microstructure of Ti 6Al $4 \mathrm{~V}$ parts produced by additive manufacturing after stress relieving and (d) final microstructure of an additively manufactured Ti 6Al 4V parts (HIPed) showing $\alpha$ - (dark) and $\beta$-phase (bright).

Second-generation titanium alloys Ti $15 \mathrm{Mo}$ and Ti $13 \mathrm{Nb}$ 13Zr for implant applications

In the present study carried out at the TU Braunschweig and the DECHEMA Forhscungsinstitut, the mechanical properties of Ti $15 \mathrm{Mo}$ and $\mathrm{Ti}$ 13Nb $13 \mathrm{Zr}$ have been investigated. Various thermo-mechanical treatments have been carried out to optimise the properties for medical applications, namely, to achieve a combination of high strength and low stiffness. To do so, different phase compositions have been used in the two alloys, e.g. $\alpha$-, $\beta$ - and $\omega$-phase in Ti $15 \mathrm{Mo}$ alloy and $\alpha$-, $\beta$ - and $\alpha^{\prime \prime}$-phase in Ti $13 \mathrm{Nb} 13 \mathrm{Zr}$, see figure 7.

The results of these investigations show that for Ti $15 \mathrm{Mo}$ the required mechanical properties' combination (compared with $\mathrm{Ti} 6 \mathrm{Al} 4 \mathrm{~V}$ ) cannot be achieved [10], whereas Ti $13 \mathrm{Nb} 13 \mathrm{Zr}$ alloy shows promising results: E.g. rolling at approx. $650^{\circ} \mathrm{C}$ (degree of deformation $\varphi \approx 1$ ) with a recrystallisation at $675^{\circ} \mathrm{C}$ ( 6 hours) and slow cooling to $625^{\circ} \mathrm{C}$ with a holding time of 8 hours followed by water quenching. This thermo-mechanical treatment led to a globular microstructure with $\alpha_{\mathrm{p}}$ and metastable niobium-enriched $\beta$-phase $\left(\mathrm{R}_{\mathrm{m}}=670 \mathrm{~N} / \mathrm{mm}^{2}, \mathrm{E}<60 \mathrm{GPa}\right)$. In a second step, a precipitation hardening was done to increase the strength by fine dispersed $\alpha$-phase in the metastable $\beta$-phase $\left(\mathrm{R}_{\mathrm{m}}=900 \mathrm{~N} / \mathrm{mm}^{2}, \mathrm{E}=84 \mathrm{GPa}\right)$. This makes the Ti $13 \mathrm{Nb} 13 \mathrm{Zr}$ alloy a good option for replacing the solute-lean $(\alpha+\beta)$-alloys in implant applications.

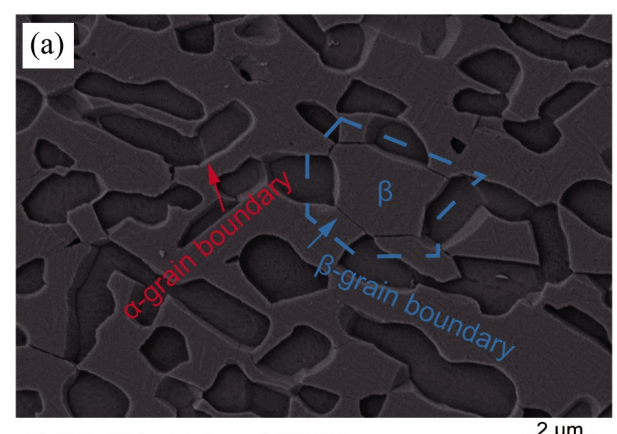

Ti-13Nb-13Zr, globular $\alpha+\beta\left(625^{\circ} \mathrm{C}\right)$

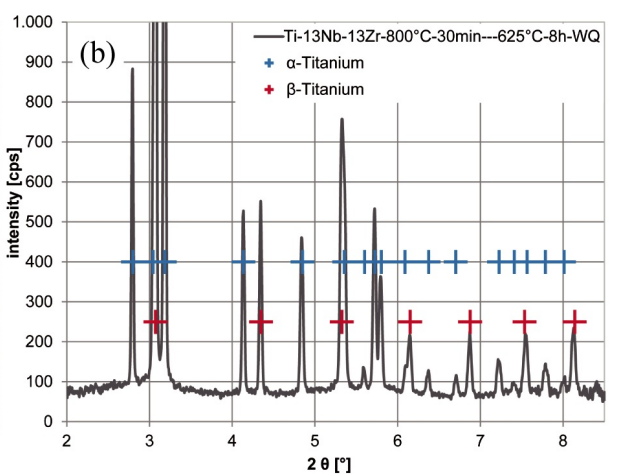

Figure 7: (a) Microstructure of rolled Ti $13 \mathrm{Nb} 13 \mathrm{Zr}$ after recrystallising at $675^{\circ} \mathrm{C}$ for 6 hours, slow cooling to $625^{\circ} \mathrm{C}$ with a holding time of 8 hours and WQ. (b) The thermo-mechanical treatment led to a globular microstructure with metastable $\beta$-phase and $\alpha_{\mathrm{p}}$-phase.

Ultrafine-grained Ti $13 \mathrm{Nb} 13 \mathrm{Zr}$ for dental implant applications

Alloys currently used for dental implants are CP-Titanium Grade 4 (implant) and Ti 6Al 4V ELI (abutment). Bacterial infections after implantation can lead to the formation of biofilms and inflammations, the so-called periimplantitis. Due to the associated bone deterioration, periimplantitis is the most common cause of implant loss. The treatment of periimplantitis (which results either in a smooth implant surface or an unsatisfactory cleaned rough surface with carbon contamination) yielded only unsatisfactory results. Therefore, reosseointegration takes place only to a lesser extent.

In the current study of AdvantIQx, the TU Darmstadt and the TU Braunschweig, the solute-rich $(\alpha+\beta)$-alloy Ti $13 \mathrm{Nb} 13 \mathrm{Zr}$ is investigated to allow its application as a dental implant material. The major advantage of $\mathrm{Ti} 13 \mathrm{Nb} 13 \mathrm{Zr}$ compared to the standard titanium alloys mentioned above is the low Young's 
modulus, especially if $\alpha^{\prime \prime}$-martensite is present in the microstructure which in turn leads to better osseointegration as the effect of stress-shielding is diminished. In addition, the strength of $\alpha^{\prime \prime}$-phase in Ti $13 \mathrm{Nb} 13 \mathrm{Zr}$ is relatively low so that low-temperature deformation is possible after annealing the alloy above $\beta$-transus followed by water quenching.

As the strength of microstructures containing large amounts of $\alpha$ "-phase in Ti $13 \mathrm{Nb} 13 \mathrm{Zr}$ is too low, the material is planned to be used in an ultrafinegrained condition, i.e. a grain-size smaller than $1 \mu \mathrm{m}$, see figure 8 . This is achieved by the application of low-temperature severe plastic deformation (ECAS) on $\alpha^{\prime \prime}$-martensitic structures, followed by a dedicated heat treatment to achieve partial $\alpha^{\prime \prime}$-martensite decomposition. In case periimplantitis occurs, a nanostructured surface will redevelop naturally after grinding and polishing of an ultrafine-grained Ti $13 \mathrm{Nb}$ 13Zr implant due to the different mechanical properties of the grain boundaries and the grains. Therefore, the risk of implant replacement after the surgical treatment is minimised and good reosseointegration is ensured.

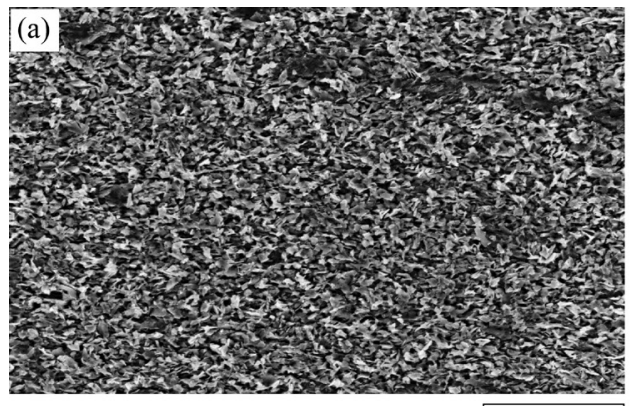

Ti $13 \mathrm{Nb} 13 \mathrm{Zr}$ after SPD

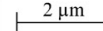

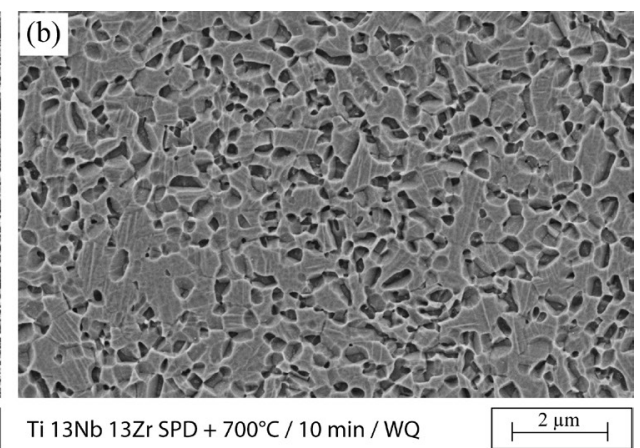

Figure 8: (a) Ti 13Nb 13Zr alloy after severe plastic deformation (SPD). The ductility is too low to fulfil the requirements of ASTM F 1713. (b) Recrystallisation at $700^{\circ} \mathrm{C}$ for 10 minutes followed by water quenching leads to a martensitic transformation of the $\beta$-phase and increased ductility. As a slight coarsening of the microstructure occurs, an optimisation of the heat treatment procedure is necessary.

\section{ECAP-treated titanium alloys}

Titanium based alloys are widely used in the biomedical area because their mechanical properties are very favourable for many applications and they offer good corrosion stability [11]. Two aspects are however critically discussed. These are (i) vanadium and aluminium as potentially cytotoxic or problematic alloying elements and (ii) the alloy specific semiconductor properties of the oxide layers. In case of high electronic conductivity this may result in redox reactions with adsorbed proteins with the danger of unfavourable immunological reactions to adsorbed proteins in non-native conformation [12,13].

Research groups at TU Dresden and AIT have studied the semiconductor properties of oxide layers on ECAP treated CP-Titanium and Ti 6Al 4V in various biologically relevant media. For a phosphate puffer system we observed for both ECAP treated materials (i) a shift to more positive flatband potentials of about $400 \mathrm{mV}$ and (ii) more importantly a strong increase in the donor densities by one and two orders of magnitude for CP-Titanium and Ti 6Al 4V, respectively in comparison to the non ECAP treated conditions, see figure 9. Galvanostatic polarization experiments supported these findings and confirmed the increased electronic conductivity of the oxide layers on the ECAP treated materials.

For the observed strong increase in the donor densities, a correlation with the dislocation densities in the metallic phases is suggested in agreement with data from Zhilyaev et al. [14] and Schafler et al. [15] who reported an increase in the dislocation density from $\sim 0.03 \times 1015 \mathrm{~m}^{-2}$ up to $2 \times 1015 \mathrm{~m}^{-2}$ for CPTitanium Grade 2 after ECAP treatment.

Electrochemical polarization experiments indicate that the negative side effect of increased electronic conductivity of air-formed oxide layers can be compensated by growing anodic oxide layers in neutral electrolytes.

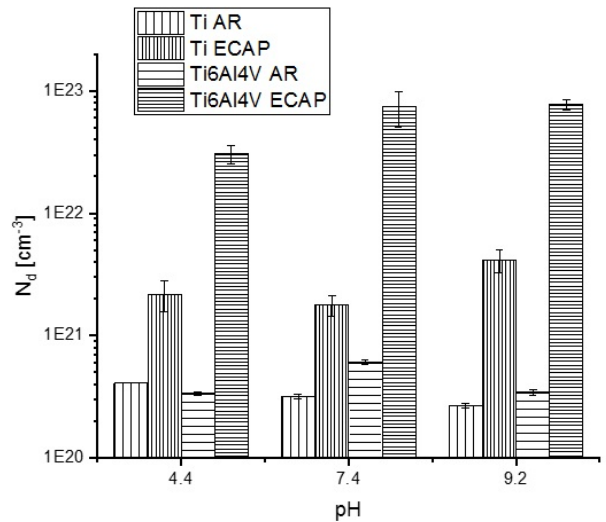

Figure 9: Donor densities Nd $\pm \mathrm{SE}$ of air-formed passive layers on $\mathrm{CP}$-Titanium (Ti) and the bi-phasic alloy $\mathrm{Ti} 6 \mathrm{Al} 4 \mathrm{~V}$ both in the as received (AR) and ECAP-treated (ECAP) state in $0.133 \mathrm{M}$ phosphate buffers (pH 4.4, 7.4, and 9.2).

\section{Additive manufacturing}

Sintering-based processing of titanium powders

Compared to processing by SLM and EBM, sintering represents a relatively old route to achieve compacts from titanium powders. On the other hand, several shaping technologies are available to form the green part, including additive ones and much of experience exists for reliable sintering. At powder metallurgy conferences, techniques like binder jetting or Fused Filament Fabrication (FFF) are more and more introduced as alternatives to SLM. Especially FFF is an ideal complement to Metal Injection Moulding (MIM) used for mass production. Single parts or small series and prototypes can be printed without need of a tool while the subsequent sintering process provides the same microstructure and, thus, same properties as the MIM part. However, while MIM is an established technology FFF is still in development, in particular in the case of titanium. Nevertheless, titanium can already be processed by FFF as shown in figure 10 (a) which displays a demonstrator part in the as-sintered stage without any post treatment. There are several current activities in Germany and at the Helholtz-Zentrum Geesthacht with regard to additive sintering-based techniques and a growing application on titanium in the near future is expected. 
Meanwhile, MIM of titanium can be called an established technology and sophisticated parts are manufactured in large volumes. As an example, figure 10 (b) displays a part applied in the field of cosmetics. The part on the right is made by MIM and consists of 81 tiny hollow pyramids with a wall thickness of $0.2 \mathrm{~mm}$. The part is soldered on the Cu part at the left. However, sintering of titanium is critical not only with respect to contaminations by oxygen and carbon. Also, iron or similar elements possibly remaining in furnaces of other devices from previous production processes can change the properties in an unwanted manner. Therefore, development of dedicated titanium alloys being robust against contaminations represents a current topic in research. For this, the exact role of contaminating elements in the alloy has to be detected as well as their influence on mechanical properties. E.g. oxygen in a Ti $6 \mathrm{Al} 4 \mathrm{~V}$ or Ti $6 \mathrm{Al} 7 \mathrm{Nb}$ alloy appears considerably less critical as implied by standards [16]. It was shown that even values of $0.35 \mathrm{wt} \%$ and higher do not introduce severe embrittlement, although the typical limit according to standards is just $0.2 \mathrm{wt} . \%$. In the case of near- $\beta$ - or $\beta$-titanium alloys used for biomedical purposes carbon from the binder results in a different issue. Because of reduced carbon solubility in the $\beta$-phase, carbides at the grain boundaries are quite easily formed introducing embrittlement. However, it could be shown in a Ti-Nb-Zr alloy that dedicated alloy design and simple heat treatment can transform these elongated carbides into spherical ones distributes over the matrix [17]. By this, ductility improves significantly.
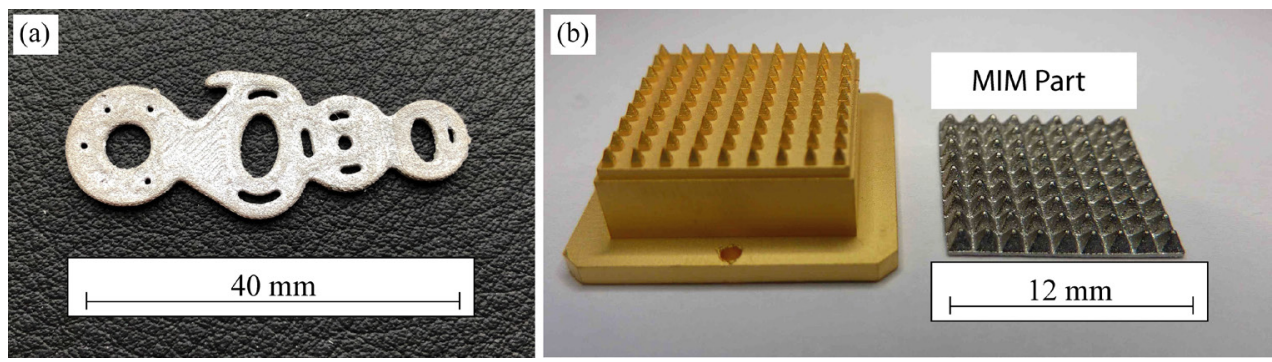

Figure 10: (a) Demonstrator part made by FFF of Ti 6AI 4V (design: Element $22 \mathrm{GmbH}$ ); (b) cosmetics product made by MIM of titanium (Element $22 \mathrm{GmbH})$.

\section{A transformation path allows novel alloy design}

The alloys used nowadays for metal-based additive manufacturing (AM) - colloquially termed 3D printing - are mostly based on compositions inherited from conventional production techniques. The strong anisotropy exhibited by alloys that solidify with cubic lattices (e.g. conventional compositions of $\mathrm{Ni}$ - or Tibased alloys) represents a deep-rooted drawback during AM [18]. The reason is that thermo-mechanical processing as implemented in traditional manufacturing for breaking up anisotropy, as well as controlling grain size and texture, is not considered in AM owing to the attractiveness of near net-shape fabrication. During AM of Ti-alloys, the strong texture of the bcc $\beta$-phase $<100>$ oriented along the SLM building direction, is transmitted to the strengthening hcp $\alpha$-phase by satisfying the Burgers orientation relationship (OR) $\{002\} \alpha \|\{110\} \beta$, see figure 11 (a) and (b).

The approach at the German Aerospace Centre (DLR) aims at tackling anisotropy by exploring alternative paths of a formation altering the regular Burgers-related $\beta$ to $\alpha$ transformation [19]. The solute $\alpha$-stabilizer La is added to commercially pure titanium (CP-Titanium) to exploit metastability around liquid-solid and solid-solid states during SLM. Besides tortuous grains, the microstructure obtained upon SLM of a Ti 2La alloy consists in extensive distributions of fine equiaxed $\alpha$ grains, see figure 11 (c). These microstructural features are not characteristic of typical transformation mechanisms usually observed in CP Ti or $\alpha+\beta$ Ti-alloys, namely neither displacive nor diffusive nucleation and growth leading to parent $\beta$ grains filled with $\alpha+\beta$ Widmanstätten structures [20]. Upon cooling of the Ti $2 \mathrm{La} \mathrm{SLM}$ as-built state from $950^{\circ} \mathrm{C}\left(\mathrm{L} 1+\beta\right.$ field) down to room temperature with $100^{\circ} \mathrm{C} / \mathrm{min}$ and $5^{\circ} \mathrm{C} / \mathrm{min}$ (i.e. thermal conditions closer to thermodynamic equilibrium than SLM, shown in figure 11 (d) and (e), respectively), formation of new $\alpha$ grains and extensive globularisation takes place resulting in recrystallised-like microstructures that do not inherit the usual SLM-induced texture of the parent $\beta$ phase. Also, grain refinement of $\alpha$ grains is obtained with increasing cooling rate.

The phase transformation kinetics during post-thermal treatment of the SLM as-built state was investigated by in situ high energy synchrotron X-ray diffraction (HEXRD). A rapid transformation $\beta$ to $\alpha$ takes place between $900^{\circ} \mathrm{C}$ and $850^{\circ} \mathrm{C}$. At the beginning of the transformation, $\mathrm{L} 1, \beta$ and $\alpha$ are present, while La reflections are absent. As was also directly confirmed by the raw diffraction images, this points to formation of $\alpha$ phase prior to the peritectic L1+ $\beta$ to La-bcc reaction given by the Ti-La equilibrium phase diagram [21] starting after about $50 \%$ completion of the diffusive $\beta$ to $\alpha$ transformation. Metallographic analysis of the SLM Ti $2 \mathrm{La}$ alloy quenched from $950^{\circ} \mathrm{C}(\mathrm{L} 1+\beta)$ shows small $\alpha$ particles at $\beta / \mathrm{L} 1$ interfaces. This, together with the results obtained from in situ HEXRD, suggests that nuclei of $\alpha$ form at $\beta / \mathrm{L} 1$ interfaces via the peritectic path $\mathrm{L} 1+\beta$ to $\alpha$, expanding during the subsequent $\beta$ to $\alpha$ transformation.

The pole figures for $\{002\} \alpha$ and $\{110\} \beta$ at $850^{\circ} \mathrm{C}$, i.e. at the end of the $\beta$ to $\alpha$ transformation, clearly showed that to a large extent, $\alpha$ does not inherit the texture of $\beta$ within this temperature range. Thus, the usual Burgers OR typical for $\beta$ to $\alpha$ transformation (and inheritance of texture by $\alpha$ ) is partially avoided.

A transformation path that offers significant texture reduction as well as equiaxed microstructures using a model Ti 2La alloy produced by SLM was discovered. This approach can be extended to titanium alloys with $\alpha+b$ microstructures as proved for Ti $1.4 \mathrm{Fe} 1 \mathrm{La}$ and represents a step-forward towards a next generation of titanium alloys for AM. Moreover, the approach shown in these investigations to adapt alloys to AM using a peritectic reaction opens up windows for target oriented alloy design in other alloy systems.
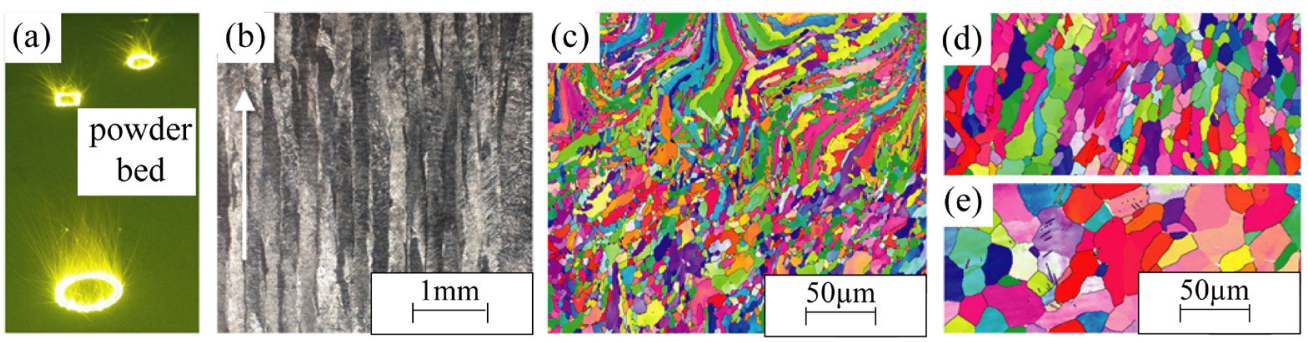

Figure 11: (a) Selective laser melting (SLM) is a powder bed-based additive manufacturing process where alloys undergo series of sharp thermal cycles tracing fast heating $(\sim 106-107 \mathrm{~K} / \mathrm{s})$ and cooling rates $(\sim 103-108 \mathrm{~K} / \mathrm{s})$. (b) Common microstructure obtained after SLM of Ti 6Al 4V showing epitaxially grown prior grains of $\beta$ phase. c) SLM of Ti 2 La leads to texture reductions along the SLM building direction pointed by the arrow in (b), owing to the formation of small equiaxed grains of a phase with multiple orientations. Post thermal treatment of the SLM as-built condition in

(c) by cooling with (d) $100^{\circ} \mathrm{C} / \mathrm{min}$ and (e) $5^{\circ} \mathrm{C} / \mathrm{min}$ from $950^{\circ} \mathrm{C}(\mathrm{L} 1+\beta$ field) down to room temperature, results in the formation of new a grains of smaller size with increasing cooling rate and extensive globularisation [19].

Additive manufacturing of titanium impellers

The additive manufacturing of components made of Ti $6 \mathrm{Al} 4 \mathrm{~V}$ by powder-bed-fusion processes, such as selective laser melting (SLM) and electron beam melting (EBM), is limited to certain dimensions depending on the machine used. Larger components can be additively manufactured using processes such as laser metal deposition (LMD), where the working atmosphere must be strictly shielded to achieve a lower $\mathrm{O}_{2}$ content. In this context, Piller Blowers \& 
Compressors is working together with the Fraunhofer IWS to develop and implement an additive manufacturing process that enables the manufacture of larger $\mathrm{Ti} 6 \mathrm{Al} 4 \mathrm{~V}$ radial compressor impellers [22], as that shown in the following figure 12.

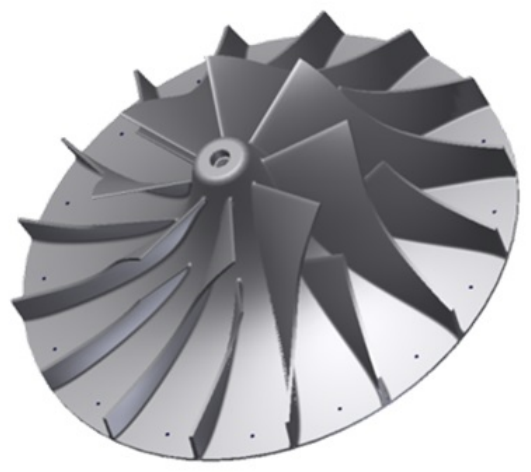

Figure 12: Piller high-speed radial impeller produced by additive manufacturing.

\section{Acknowledgements}

Contributions to this plenary paper, i.e. the content and figures presented in the sections 2,3 and 4 , from different industrial companies, research organisations and universities are gratefully acknowledged: J. Scherer, J. Niewolik (AdvantIQx), M. Krystian, B. Mingler, L. Sajti (AIT Austrian Institute of Technology), S. Lederer, W. Fürbeth (DECHEMA Forschungsinstitut), P. Barriobero-Vila, J. Gussone, J. Haubrich, G. Requena (DLR), F. Brückner (Fraunhofer IWS), V. Güther (GfE Metalle und Materialien), T. Ebel (Helmholtzzeutrum Geesthacht), A. Danzig, A. El-Chaikh, D. Muenter (Liebherr-Aerospace Lindenberg), D. Wolter (litos), M. Balzer, T. Witulski (Otto Fuchs), M. Mhaede (Piller Blowers \& Compressors), F. Brunke, F. Haase, L. Klinge, P. Lang (Technische Universität Braunschweig), F. Chi, F. Hoppe (Technische Universität Darmstadt), M. Franz D. Scharnweber, C. Wolf-Brandstetter, (Technische Universität Dresden), H.-J. Christ, V. Macin, C. Schmidt, P. Schmidt (Universität Siegen), S. Voigt and T. Sahin (VACUCAST) added their results to highlight some of the German titanium research activities of the last four years.

\section{References}

[1] C. Siemers, J. Kiese, Proceedings of the 13th World Conference on Titanium (Ti-2015), San Diego, USA, 2016, 41-50.

[2] C. Siemers, D. Wolter, H. Sibum, German Patent No. 102014010 032.4, 2016.

[3] D.R. Williams, Chemical Reviews 72 (3) (1972) 203-213.

[4] C. Siemers, F. Haase, F. Brunke, Biomedical Engineering 64 (1) (2019) 66-68.

[5] C. Siemers, M. Bäker, F. Brunke, D. Wolter, H. Sibum, in: F. H. Froes, M. Qian (eds.): Titanium in Medical and Dental Applications, Elsevier, 2018, 477492.

[6] A. Berg, doctoral thesis, Institute of Metallurgy and Materials Engineering, Brandenburgische Technische Universität Cottbus, Germany, 2000.

[7] M. Sozanska, Mater Sci Eng, 22 (2011) 1-11.

[8] V. Macin, H.J. Christ, TMS 2016, Annual Meeting, Supplemental Proceedings, Nashville, TN, USA, 2016, 673-684.

[9] P. Schmidt, doctoral thesis, Institute for Materials Engineering, University of Siegen, Germany, 2018.

[10] F. Brunke, C. Siemers, J. Rösler, Proceedings of the 13th World Conference on Titanium (Ti-2015), San Diego, USA, 2016, 929-934.

[11] B. Mingler, M. Krystian, M. Bammer, Proceedings of the 11th World Conference on Titanium (Ti-2011), Beijing, China, 2012, $2067-2071$.

[12] D. Scharnweber, R. Beutner, S. Rößler, H. Worch, J. Mater. Sci. Mater. Med. 13 (2002) 1215-1220.

[13] S.E. Pust, D. Scharnweber, S. Baunack, G. Wittstock, J. Electrochem. Soc. 154 (2007) C508.

[14] A. Zhilyaev, N. Parkhimovich, G. Raab, V. Popov, V. Danilenko, Rev. Adv. Mater. Sci. 43 (2015) 61-66.

[15] E. Schafler, K. Nyilas, S. Bernstorff, L. Zeipper, M. Zehetbauer, T. Ungàr, Zeitschrift Fur Krist. 1 (2006) 129-134.

[16] A. Amherd Hidalgo, W. Limberg, T. Ebel, R. Frykholm, E. Carreno-Morelli, F. Pyczak, Key Engineering Materials, Titanium Powder Metallurgy and Additive Manufacturing 770 (2018) 80-86.

[17] P. Xu, T. Ebel, W. Limberg, A. Amherd Hidalgo, F. Pyczak, R. Willumeit-Römer, Proceedings of the Euro PM 2018, Bilbao, Spain, 2018.

[18] P.C. Collins, D.A. Brice, P. Samimi, I. Ghamarian, H.L. Fraser, Annu. Rev. Mater. Res. 46 (2016) 1-18.

[19] P. Barriobero-Vila, J. Gussone, A. Stark, N. Schell, J. Haubrich, G. Requena, Nature Communications 9 (2018) 3426.

[20] G. Lütjering, J.C. Williams, Titanium, Springer, 2007.

[21] N. Mattern, Y. Yokohama, A. Mizuno, J.H. Han, O. Fabrichnaya, M. Richter, S. Kohara, Calphad 52 (2016) 8-20.

[22] https://www.piller.de/de/downloads 